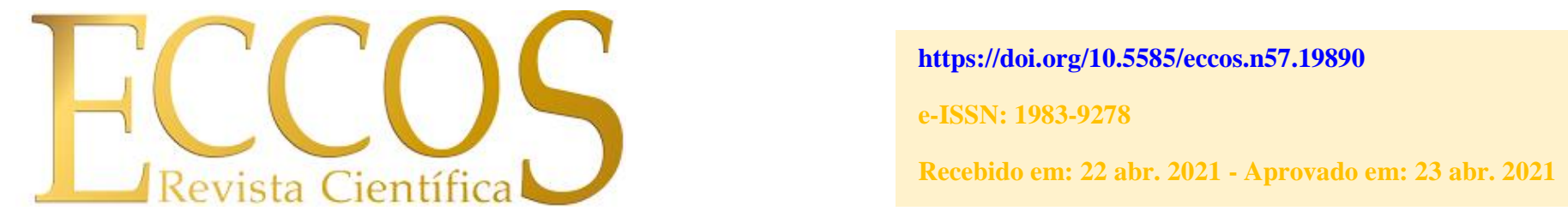

Check for updates

\title{
GÓES, Natália Moraes; BORUCHOVITCH, Evely. Estratégias de aprendizagem: como promovê-las? Petrópolis, RJ: Vozes, 2020. 126 p.
}

\author{
Elisangela Aparecida Bulla Ikeshoji \\ Doutoranda em Educação (Bolsista CAPES) \\ Universidade Nove de Julho - UNINOVE. \\ São Paulo, São Paulo - Brasil. \\ elisangela.bulla@gmail.com \\ Adriana Aparecida de Lima Terçariol \\ Doutora em Educação \\ Universidade Nove de Julho - UNINOVE. \\ São Paulo, São Paulo - Brasil. \\ atercariol@gmail.com
}

\section{Para citar - (ABNT 6023:2018)}

IKESHOJI, Elisangela Aparecida Bulla; TERÇARIOL, Adriana Aparecida de Lima. Eccos Revista Cientifica, São Paulo, n. 57, p. 1-6, e19890, abr./jun., 2021. Resenha da obra de GÓES, Natália Moraes; BORUCHOVITCH, Evely. Estratégias de aprendizagem: como promovê-las? Petrópolis, RJ: Vozes, 2020. 126 p. https://doi.org/10.5585/eccos.n57.19890.

A presente obra escrita por Natália Moraes Góes, doutora em educação pela Universidade Estadual de Campinas (Unicamp), professora colaboradora do departamento de educação da Universidade Estadual de Londrina (UEL) e Evely Boruchovitch, doutora em educação pela University of Southern Califórnia, Los Angeles, professora titular do Departamento de Psicologia Educacional da Faculdade de Educação da Universidade Estadual de Campinas (Unicamp), ambas membros do Grupo de Estudos e Pesquisas em Psicopedagogia (Gepesp/Unicamp), traz, numa linguagem simples, reflexões a respeito das estratégias de aprendizagem: cognitivas e metacognitivas, e sobre como promovê-las.

Considera-se que as reflexões discorridas no texto por Góes e Boruchovitch (2020, p. 83) são desenvolvidas a partir da seguinte problemática: "Para que os estudantes consigam selecionar as estratégias de aprendizagem cognitivas mais adequadas para aprender eles precisam saber como aprendem, o que precisam fazer para aprender e como podem potencializar a própria aprendizagem". E estão estruturadas em duas partes: numa as questões 
da aprendizagem metacognitivas e noutra, as cognitivas. Porém, são precedidas de Apresentação e, por último, Posfácio e Agradecimentos.

A obra está organizada em duas partes. A Parte I compreende as "estratégias de aprendizagem metacognitivas - como promovê-las no contexto educativo?” e engloba os capítulos: "1) O que são estratégias de aprendizagem? Como fomentá-las nos diferentes segmentos da escolarização?; 2) A estratégia metacognitiva de planejamento - como estabelecer metas de estudo e aprendizagem?; 3) O monitoramento metacognitivo e a estratégia de autoquestionamento - suas vantagens para aprendizagem; 4) As estratégias de regulação da motivação - como ensinar os alunos a manter-se motivados no contexto educativo?". A Parte II aborda as "estratégias de aprendizagem cognitivas - como promovê-las no contexto educativo?" e abrange os capítulos: "5) Como sublinhar corretamente? Os benefícios do sublinhar para a aprendizagem; 6) Como elaborar bons resumos para estudar e aprender melhor?; 7) Os mapas conceituais e seu impacto na aprendizagem significativa - da teoria à implementação dessa estratégia”.

E, à medida que se discute, em cada um destes capítulos, os fundamentos teóricos, também são apresentadas atividades que orientam os professores e estudantes na elaboração e desenvolvimento de atividades autorreflexivas, que visam promover a utilização de estratégias de aprendizagem.

No capítulo 1, pontuam, de maneira geral como promover as estratégias de aprendizagem metacognitivas: planejamento, monitoramento e regulação; e cognitivas: ensaio, elaboração e organização, assim como fecundá-las no ensino fundamental, médio e superior. Expõem-se também, caraterísticas a respeito da história, classificações, definições e alguns exemplos de intervenções desenvolvidas em contexto escolares, demonstrando o uso de estratégias de aprendizagem.

Apresentam os procedimentos compreendidos nas estratégias metacognitivas, sendo elas: planejamento - abrange o plano de ação com elaboração de metas antes mesmo de se enfocar a aprendizagem; monitoramento - implica avaliar durante todo o processo de aprendizagem, no que diz respeito à compreensão sobre algo, quando necessário, voltando-se para a análise das metas estabelecidas; e, regulação - possibilita transformar o comportamento empregado para aprender, a partir do monitoramento, visando alcançar a meta estabelecida no planejamento.

Também abordam os procedimentos referentes às estratégias cognitivas: ensaio - busca captar de maneira passiva a informação via a exposição repetitiva da informação, já as ativas, procuram captar a construção de signos; elaboração - envolve adicionar ou modificar ou 
relacionar algo novo com o que já se sabe, e, organização - tem o foco em conferir uma nova organização e relacionar a conceitos aprendidos, tornando-os mais significativos. Ainda, pontuam, as estratégias cognitivas de ensaio que tratam a informação de maneira mais superficial, o que difere da estratégia cognitiva de elaboração e organização, visto que, o processamento da informação tem possibilidade de ser trabalhado de maneira mais profunda.

Reforçam, neste capítulo, que as estratégias de aprendizagem cognitivas e metacognitivas estão intimamente relacionadas, sendo essencial saber identificar as variedades de estratégias disponíveis para aprender, assim como empregá-las e reconhecer em quais momentos da aprendizagem uma pode ser mais vantajosa que a outra. Nesse sentido, sinalizam que os estudantes quando se utilizam dessas estratégias, são autorregulados e elas são aprendidas, tendo o professor o papel fundamental de estimular e orientá-los nesse processo. Evocam não ser uma tarefa simples, identificar quais, como e em quais momentos utilizar-se das habilidades autorregulatórias e que pesquisas recentes têm demonstrado que as diferenças individuais na aprendizagem ocorrem devido à falta de habilidade autorregulatória, uma vez que a maioria dos estudantes domina poucas estratégias de aprendizagem e encontram dificuldades de desenvolver esse processo, assim como parecem conhecer pouco sobre a cognição e suas potencialidades.

Já no capítulo 2, focalizam, em específico, a estratégia metacognitiva de planejamento, e como estabelecer metas de estudo e aprendizagem, além de seus benefícios. Segundo as autoras, para utilizar-se da estratégia metacognitiva, num processo de autorregulação, visando otimizar e alcançar as metas estabelecidas para aprender, é preciso exercer controle sobre a própria cognição, assim como motivação, comportamento, ambiente, permeado por valores e crenças pessoais.

As autoras dialogam sobre a estratégia de aprendizagem metacognitiva com Bandura (1986) que nomeia de autorregulação como um processo cíclico composto pelas fases de: planejamento, execução e autorreflexão. Assinalam ser imprescindível, em cada uma destas fases, ocorrer o monitoramento e avaliação, objetivando identificar as causas para os sucessos e/ou fracassos na aprendizagem. As metas de planejamento para aprendizagem devem ser estabelecidas a partir dos seguintes critérios: específica, mensurável, quando coloca o estudante em ação, realista e passível de ser alcançada, pois durante a execução das metas estabelecidas, se for necessário, o plano deve ser revisto e avaliado constantemente, para não perder de vista o objetivo pretendido. Sendo, portanto, fundamental, neste processo de autorregulação a autorreflexão, o autojulgamento e a autorreação. Momento em que o estudante examina se deve 
prosseguir com novos conteúdos ou retomar alguns aspectos do conteúdo ainda não aprendido de forma satisfatória ou desejada.

No capítulo 3, discutem a estratégia de aprendizagem metacognitiva de monitoramento compreendida pela estratégia de autoquestionamento. Evidenciam que o monitoramento metacognitivo e autorregulado é realizado por meio da reflexão profunda a respeito da aprendizagem e dos processos pelos quais se aprende. Salientam que, ao exercer o controle sobre a aprendizagem, é essencial utilizar-se da estratégia metacognitiva de autoquestionamento.

Para as autoras, o autoquestionamento leva em consideração o julgamento que se faz frente a uma determinada tarefa compreendida, dentre as seguintes características: subestimar, coerência ou superestimar. Por isso, o monitoramento metacognitivo autorregulado oferece condições de pensar frente às situações de aprendizagem, de modo que o desempenho real e estimado estejam o mais próximo possível. Uma situação em que se subestima a capacidade de realização sobre algo, pode levar a uma situação de desistência, antes mesmo de iniciar uma tarefa ou superestimar a capacidade e não dar conta dela. Nesse sentido, apresentam a vantagem da estratégia de autoquestionamento, ao ser utilizada antes, durante ou depois da realização de uma tarefa, o que possibilita modificar hábitos de estudos.

Encerram, a primeira parte da obra, com o capítulo 4. Nele, apresentam as estratégias metacognitivas de regulação articulada à motivação. Sinalizam que as metas estabelecidas requerem constante monitoramento e regulação, de comportamentos ou ações que possam influenciar negativamente na maximização da aprendizagem. Na estratégia de regulação, compreendem-se três dimensões sobre motivação: conhecimento sobre a própria motivação; monitoramento atento e consciente, no curto e longo prazo, a respeito da própria motivação; e, controle sobre a natureza da motivação. E por fim, elencam situações, comportamentos e ações que podem estimular e buscar compreender melhor as estratégias de aprendizagem, quando se observa quem já aplica esta estratégia de regulação; alguém mais experiente neste processo que possa ajudar os iniciantes; os professores; os colegas de turma; livros; revistas; periódicos.

Finalizam as discussões sobre as estratégias de aprendizagem metacognitivas de planejamento, monitoramento e regulação e discutem na segunda parte, nos capítulos 5, 6 e 7, as estratégias de aprendizagem cognitivas de ensaio, elaboração e organização.

No capítulo 5 abordam como estratégia de aprendizagem o sublinhar corretamente e seus benefícios para a aprendizagem cognitiva de ensaio. Destacam que o ato de grifar partes de um material é considerada uma das estratégias mais populares entre os estudantes, no 
entanto, as autoras lembram que na maioria das vezes, não a utilizam em potencial para fomentar a aprendizagem.

No entanto, o sublinhar é característico e pode ser uma primeira etapa, de codificar e de armazenar a informação, para uma aprendizagem mais profunda - isso envolve construir mentalmente um texto coerente, distinguir o conteúdo principal do secundário -, pois é preciso sublinhar no material apenas o que necessita ser apreendido, sem perder de vista o objetivo desse procedimento. É considerada uma etapa fundamental, pois quando for preciso retornar ao material, a título de recuperação da informação, pode-se dar atenção às partes essenciais destacadas. Ao contrário, para Mcandrew (1983 apud GÓES; BORUCHOVITCH, 2020, p. 85) “as marcações excessivas e irrelevantes apresentam efeitos negativos para a aprendizagem”. Nesse momento, as autoras apresentam os cinco passos para o sublinhar: i) análise rápida do texto e dos seus tópicos para identificar o assunto abordado; ii) leitura cuidadosa de cada parágrafo; iii) sublinhar os pontos principais; iv) com base no que foi sublinhado, revisar o texto todo; v) momento de aprender o conteúdo. Elas consideram que o conteúdo efetivamente aprendido é armazenado na memória de longo prazo.

No capítulo 6, a ênfase é dada ao resumo, pois se trata de estratégia cognitiva de elaboração. Abordam que o ato de resumir consiste em escrever com suas próprias palavras as ideias principais do texto, sem alterar a mensagem que está sendo transmitida, não incluindo críticas, além da necessidade de se ter a clareza sobre quem será o destinatário do resumo elaborado. Portanto, destacam que o resumir envolve duas etapas principais: "a compreensão do texto original e a elaboração de um texto pessoal. Não é possível construir bons resumos sem a compreensão global do texto" (FRIEND, 2000 apud GÓES; BORUCHOVITCH, 2020, p. 99). E sinalizam a importância de conhecer o autor e seu posicionamento teórico, antes de elaborar um resumo.

No capítulo 7, o último da obra, as autoras apresentam mapas conceituais e seu impacto na aprendizagem significativa, desde a teoria à implementação desta estratégia cognitiva de organização. Neste capítulo, expõe-se um texto contendo a fundamentação teórica do mapa conceitual, baseada na Teoria da Aprendizagem significativa e os relatos das experiências desenvolvidas em diferentes contextos: estudantes do ensino médio e ensino superior, professores do ensino fundamental e ensino médio.

Segundo Góes e Boruchovitch (2020, p. 117) “O conhecimento prévio, na Teoria da Aprendizagem Significativa, é considerado o fator mais importante da aprendizagem, uma vez que, servirá de âncora ou suporte para a aquisição de novos conhecimentos". Por isso, frente a um novo conteúdo, orientam selecionar conceitos-chave, utilizando-se de palavras próprias, 
conectando-as com outros conceitos já compreendidos. Isso dá subsídio para a construção do mapa conceitual. Ao final deste capítulo, são apresentados relatos de experiências, evidenciando que os estudantes, ao utilizarem mapas conceituais, beneficiam-se dessa estratégia cognitiva de organização, ainda que muitos não façam o uso das potencialidades deste tipo de aprendizagem, assim como professores que desconhecem a teoria que fundamenta esta estratégia ou consideram que incluí-la na prática pedagógica demanda muito tempo. No entanto, apresentam situações em que professores, ao conhecerem a teoria, utilizam-na como recurso cognitivo de aprendizagem, quando buscam aprender um novo conteúdo. Enfim, Góes e Boruchovitch (2020, p. 122) mencionam: “[...] o que se observa, ainda hoje, é a ausência de um olhar mais atento aos conhecimentos metacognitivos dos estudantes e uma maior preocupação com a transmissão do conteúdo".

A análise sobre os aspectos abordados na obra instiga conhecer mais sobre o assunto, levando o leitor a compreender que o estímulo dos estudantes já no início da vida escolar para lidar com as estratégias de aprendizagem cognitiva e metacognitiva, pode ser desenvolvido com a orientação do professor. Entende-se que o conhecimento metacognitivo é essencial para a aprendizagem, e que por meio dele, torna-se possível escolher as estratégias mais apropriadas para o estilo de aprendizagem, e assim, interferir e modificar ações durante todo o processo de construção de novos conhecimentos. O conteúdo abordado nesta obra é fecundo para auxiliar estudantes e professores no processo de ensino e aprendizagem e no cotidiano da sala de aula.

\section{Agradecimento}

O presente trabalho foi realizado com apoio da Coordenação de Aperfeiçoamento de Pessoal de Nível Superior - Brasil (CAPES) - Código de Financiamento 001. 